\title{
Liquens parmelioides eciliados (Parmeliaceae, Ascomycota) em costões rochosos dos estados do Paraná e Santa Catarina, Brasil
}

\author{
Alice da Cruz Lima Gerlach ${ }^{1,2}$ e Sionara Eliasaro ${ }^{1}$
}

Recebido em 11/01/2012. Aceito em 27/04/2012

\begin{abstract}
RESUMO
(Liquens parmelioides eciliados (Parmeliaceae, Ascomycota) em costões rochosos dos estados do Paraná e de Santa Catarina, Brasil). O levantamento das espécies de liquens parmelioides eciliados que ocorrem em costões rochosos dos estados do Paraná e de Santa Catarina revelou a presença de doze espécies pertencentes aos gêneros Canoparmelia (1), Hypotrachyna (2), Parmotrema (4), Pseudoparmelia (1) e Xanthoparmelia (4). Entre as novas ocorrências estão Parmotrema mordenii e Xanthoparmelia subramigera para o Paraná e para Santa Catarina, Pseudoparmelia cubensis e Xanthoparmelia catarinae para o Paraná, enquanto que Hypotrachyna osseoalba, Parmotrema dactylosum e P. endosulphureum são para Santa Catarina. São apresentadas chave de identificação, descrições, comentários e ilustrações.
\end{abstract}

Palavras-chave: liquens, litoral, taxonomia

\begin{abstract}
(Parmelioid eciliate lichens (Parmeliaceae, Ascomycota) from rocky shores of Paraná and Santa Catarina, Brazil). A survey of parmelioid eciliate lichen species occurring on rocky shores, from the states of Paraná and Santa Catarina, revealed the presence of twelve species in the following genera: Canoparmelia (1), Hypotrachyna (2), Parmotrema (4), Pseudoparmelia (1) and Xanthoparmelia (4). New records are Parmotrema mordenii and Xanthoparmelia subramigera for Paraná and Santa Catarina, Pseudoparmelia cubensis and Xanthoparmelia catarinae for Paraná, and Hypotrachyna osseoalba, Parmotrema dactylosum and P. endosulphureum for Santa Catarina. An identification key, descriptions, comments and illustrations are provided.
\end{abstract}

Key words: coast, lichens, taxonomy

\section{Introdução}

Os fungos liquenizados parmelioides representam cerca de $75 \%$ das espécies descritas na família Parmeliaceae e caracterizam-se por apresentar talos principalmente foliosos, com rizinas na superfície inferior, apotécios laminais, ascos do tipo Lecanora e ascósporos simples e hialinos (Crespo et al. 2001). Os cílios são feixes de hifas, geralmente carbonizadas (Barbosa et al.2009), que podem ser encontradas nas margens dos lobos e anfitécios dos apotécios (Kirk et al. 2008). Neste grupo, oito gêneros possuem as margens dos lobos ciliadas, em cinco gêneros os cílios podem ou não estar presentes e pelo menos 11 gêneros não apresentam cílios (Elix 1993, Blanco et al. 2004, Crespo et al. 2010, Divakar et al. 2010). Apesar de a presença ou ausência de cílios não refletir relações filogenéticas, visto que estes foram perdidos e adquiridos várias vezes ao longo da evolução (Crespo et al. 2011), este caráter foi amplamente utilizado para circunscrever gêneros em fungos parmelioides (Elix 1993), e mostra-se útil para delimitar grupos morfológicos entre estes liquens.

Segundo o Ministério do Meio Ambiente (2010) os costões rochosos estão incluídos entre os ambientes menos pesquisados no país e de acordo com Marcelli (1998), são conhecidas apenas cerca de 25 das 200 espécies de fungos liquenizados esperadas para este ambiente no Brasil.

Osorio \& Fleig (1984a; 1984b) fizeram as primeiras referências para liquens em costões rochosos do sul do país, e somente após cerca de três décadas Gumboski \& Eliasaro (2011) descrevem uma espécie nova para costões rochosos em Santa Catarina e Gumboski (2011) estuda o gênero Cladonia P. Browne em costões do Paraná e Santa Catarina. Recentemente Benatti et al. (2008), Benatti \& Marcelli (2008; 2009a; 2009b), Marcelli et al. (2008), Marcelli \& Benatti (2008; 2010a; 2010b) apresentam uma série de

\footnotetext{
${ }^{1}$ Universidade Federal do Paraná, Departamento de Botânica, Laboratório de Liquenologia, Curitiba, PR, Brasil

${ }^{2}$ Autor para correspondência: alice_gerlach@yahoo.com.br
} 
estudos para o gênero Parmotrema A. Massal que incluem costões rochosos do litoral centro-sul de São Paulo.

A escassez de dados sobre as espécies de fungos liquenizados que se desenvolvem sobre costões rochosos, nos levou a propor este trabalho, o qual corresponde ao primeiro levantamento das espécies parmelioides nestes ambientes nos estados do Paraná e Santa Catarina. Neste trabalho são apresentados os resultados dos gêneros parmelioides eciliados.

\section{Material e métodos}

As coletas foram realizadas em costões rochosos de 10 municípios ao longo do litoral do Paraná (quatro localidades) e de Santa Catarina (20 localidades) e seguiram a metodologia descrita em Brodo et al. (2001). Em laboratório, os materiais foram secos em temperatura ambiente ou estufa a baixa temperatura e herborizados. Depois de herborizados e identificados foram incorporados ao Herbário UPCB da Universidade Federal do Paraná. Foram também analisados espécimes do herbário ICN, da Universidade Federal do Rio Grande do Sul.

As análises morfológicas foram realizadas utilizando microscópio estereoscópico $(20-50 \times)$ e para as análises anatômicas, cortes feitos à mão livre foram observados em microscópio fotônico (400-1000×), ambos com ocular com retículo graduado. Para a identificação de metabólitos secundários de importância taxonômica foram utilizados: testes de coloração de córtex e medula e observação do talo em lâmpada UV de acordo com Taylor $(1967,1968)$ e cromatografia em camada delgada (CCD) seguindo Culberson \& Ammann (1979) e Elix \& Ernst-Russell (1993).

\section{Resultados e discussão}

Nos costões rochosos do Paraná e Santa Catarina foram encontradas 12 espécies de fungos liquenizados parmelioides distribuídas em cinco gêneros: Canoparmelia texana (Tuck.) Elix \& Hale, Hypotrachyna livida (Taylor) Hale, H. osseoalba (Vain.) Y.S. Park \& Hale, Parmotrema dactylosum Fleig, P. endosulphureum (Hillmann) Hale, P. mordenii (Hale) Hale, P. tinctorum (Despr. ex Nyl.) Hale, Pseudoparmelia cubensis (Nyl.) Elix \& T.H. Nash, Xanthoparmelia catarinae Hale, X. neopropaguloides Hale, X. plittii (Gyeln.) Hale e X. subramigera (Gyeln.) Hale. Além destas, foram também encontrados alguns espécimes de Punctelia Krog que aparentemente pertencem a uma espécie nova, mas ainda são necessários mais exemplares para uma análise conclusiva.

Todas as espécies foram encontradas nos costões rochosos de Santa Catarina, sendo que cinco são novas ocorrências para o Estado: Hypotrachyna osseoalba, Parmotrema dactylosum, P. endosulphureum, P. mordenii e Xanthoparmelia subramigera. No entanto, no Paraná foram encontradas somente quatro espécies, todas representando novas citações para o Estado: Parmotrema mordenii, Pseudoparmelia cubensis, Xanthoparmelia catarinae e X. subramigera.

Com exceção de Parmotrema tinctorum e de P. mordenii, citadas para costões rochosos respectivamente por Osorio \& Fleig (1984b) para o Rio Grande do Sul e por Marcelli \& Benatti (2010a) para São Paulo, todas as demais espécies encontradas são novidades para os costões rochosos brasileiros.

\section{Chave artificial para liquens parmelioides eciliados em costões rochosos no Paraná e Santa Catarina}

1a. Talo verde amarelado, córtex superior K- (ácido úsnico cortical)

2a. Superfície inferior negra. ..9. Xanthoparmelia catarinae

2b. Superfície inferior marrom

3a. Medula K+ marrom avermelhado (ácidos succinprotocetrárico e fumarprotocetrárico)

3b. Medula K+ amarelo (ácidos estíctico e conestíctico)

4a. Lacínias 0,9-1,2 $\mathrm{mm}$ de largura. 12. Xanthoparmelia subramigera

4b. Lacínias $0,3-0,8 \mathrm{~mm}$ de largura...................................................... 10. Xanthop 11. Xanthoparmelia plittii

5a. Rizinas dicotômicas

6a. Sem propágulos vegetativos.

2. Hypotrachyna livida

6b. Com pústulas que originam sorédios granulares 3. Hypotrachyna osseoalba

5b. Rizinas simples

7a. Medula amarela clara a escura

8a. Isidiado.

5. Parmotrema endosulphureum

8b. Sem propágulos vegetativos 8. Pseudoparmelia cubensis

7b. Medula branca

9a. Isidiado 7. Parmotrema tinctorum

9b. Com pústulas ou sorais

10a. Com pústulas 4. Parmotrema dactylosum

10b. Com sorais

11a. Sorais lineares marginais

6. Parmotrema mordenii

11b. Sorais orbiculares laminais 1. Canoparmelia texana 
1. Canoparmelia texana (Tuck.) Elix \& Hale, Mycotaxon 27: 279. 1986.

Parmelia texana Tuck., Amer. J. Sci. Arts, Ser. 2 25: 424. 1858.

Fig. 1

Talo lobado, adnato, 9,0 cm de diâmetro, membranáceo, verde acinzentado. Lobos de contíguos a sobrepostos, 3,5-5,0 mm de largura, ramificação irregular, margem lisa, de inteira a pouco crenada, plana, ápice arredondado, lacínulas e cílios ausentes. Superfície superior opaca, geralmente com fissuras transversais tornando-se irregulares, de lisa a raramente foveolada no ápice dos lobos, tornando-se rugosa em direção ao centro do talo, densamente sorediada na região central; máculas tênues, em geral puntiformes a lineares, raramente reticulares, laminais; pruína ausente. Sorais abundantes laminais e submarginais, orbiculares, tornam-se coalescentes quando localizados sobre as dobras do talo e nas submargens dos lobos; sorédios granulares. Medula branca. Superfície inferior negra, de lisa a pouco rugosa, com margem estreita, $1,0-2,5 \mathrm{~mm}$ de largura, marrom escura, de lisa a papilada, errizinada e com fissuras lineares; rizinas freqüentes, simples, com distribuição homogênea, de negras a raramente castanhas quando próximas à margem, 1,5 × 0,2 mm. Apotécios e Picnídios ausentes.

Química - Testes de coloração: córtex superior $\mathrm{K}+$ amarelo, UV-; medula $\mathrm{K}-, \mathrm{C}-$, $\mathrm{KC}+$ rosa evanescente, UV-. CCD: atranorina (córtex superior) e ácido divaricático (medula).

Distribuição - África, América do Norte, América Central, América do Sul, Ásia e Oceania (Hale 1976). Na América do Sul: Argentina (Osorio 1982), Brasil, Chile, Peru, Uruguai e Venezuela (Hale 1976). No Brasil: MG (Hale 1976), MS (Fleig \& Riquelme 1991), PR (Eliasaro 2006), RS, SC e SP (Hale 1976).

Comentários - Canoparmelia texana se caracteriza pelos sorais orbiculares laminais a submarginais, superfície inferior negra e presença de ácido divaricático na medula.

Canoparmelia crozalsiana (B. de Lesd.) Elix \& Hale é morfologicamente similar por possuir talo sorediado e lobos subirregulares, de 3,0-6,0 mm de largura (Hale 1976). Contudo, C. crozalsiana é facilmente distinguível de $C$. texana por apresentar a superfície superior fortemente foveolada e sorédios mais finos, farinhosos; além disso, C. crozalsiana possui química medular distinta, apresentando ácidos do complexo estíctico (Elix 1994a; Nash \& Elix 2002a).

Canoparmelia texana possui ampla distribuição geográfica e é especialmente comum em ambientes urbanizados no sul e sudeste do Brasil (Marcelli 1998). É uma das espécies mais comuns em Curitiba ocorrendo tanto sobre forófitos nativos quanto exóticos (Eliasaro et al. 2009). No entanto, em costões rochosos, a espécie é rara, tendo sido coletado somente um exemplar, em local protegido do spray marinho e ensolarado.

Espécime examinado - BRASIL. Santa Catarina: Imbituba, Praia de Itapirubá, 19/II/2010, E. Gumboski \& F. Beilke 1747 (UPCB).
2. Hypotrachyna livida (Taylor) Hale. Smithsonian Contributions to Botany 25: 41. 1975.

Parmelia livida Taylor, London J. Bot. 6: 171. 1847.

Fig. 2

Talo laciniado, adnato, 4,0-10,0 cm de diâmetro, subcoriáceo, de branco acinzentado a esverdeado. Lacínias contíguas, sublineares, 0,6-1,6 mm de largura, ramificação subdicotômica, margem lisa, inteira, de plana a geralmente pouco involuta, com ápice truncado, lacínulas e cílios ausentes. Superfície superior brilhosa, contínua, lisa; máculas ausentes; pruína ausente. Propágulos vegetativos ausentes. Medula branca. Superfície inferior negra, de lisa a pouco rugosa, margem estreita, até 1,0 $\mathrm{mm}$ de largura, negra a marrom escura, lisa, densamente rizinada; rizinas frequentes, com ramificação principalmente dicotômica, raramente simples, com distribuição homogênea, negras, $0,2-1,5 \times 0,08-0,10 \mathrm{~mm}$. Apotécios ausentes. Picnídios em geral ausentes, abundantes apenas no espécime S. Eliasaro 4992, submarginais a laminais; conídios bifusiformes, 5,0-7,0 × 1,0 $\mu \mathrm{m}$.

Química - Testes de coloração: córtex superior $\mathrm{K}+$ amarelo, UV-; medula $\mathrm{K}-$, $\mathrm{C}-$, $\mathrm{KC}+$ rosa, UV+ branco azulado. CCD: atranorina (córtex superior), ácidos livídico, 4-O-metilfisódico e colensóico (medula).

Distribuição - América do Norte (Hale 1975), América do Sul (Lynge 1914, como Parmelia osseo-albida Lynge) e Ásia (Divakar \& Upreti 2003). Na América do Sul: Argentina, Brasil, Uruguai e Venezuela (Hale 1975). No Brasil: MG (Hale 1975), MS (Fleig \& Riquelme 1991), PR (Eliasaro et al. 1998), RJ (Hale 1975), RS (Lynge 1914, como P. osseo-albida), SC e SP (Hale 1975).

Comentários - Hypotrachyna livida se caracteriza pelo talo laciniado, frouxo-adnato, sem propágulos vegetativos e pela medula com ácidos do grupo livídico e colensóico.

Hypotrachyna palmarum (Lynge) Hale é morfologicamente muito similar a $H$. livida, por possuir lacínias sublineares a subirregulares com ramificação dicotômica e ausência de propágulos vegetativos; contudo, se diferenciam pela química medular. Enquanto $H$. palmarum possui os ácidos norcolensóico e colensóico, $H$. livida apresenta os ácidos livídico e 4-O-metilfisódico (Sipman et al. 2009).

A maioria dos autores que descreve Hypotrachyna livida não indica medula UV+ (Hale 1975; Eliasaro et al. 1998; Divakar \& Upreti 2003; Sipman et al. 2009). Spielmann \& Marcelli (2008) são os únicos autores que encontraram fluorescência medular em exemplares desta espécie do Rio Grande do Sul, em concordância com o observado nos exemplares analisados aqui.

Hypotrachyna livida é comum no sudeste do Brasil e no Uruguai, entre 500 a 2.500 metros de altitude ocorrendo como corticícola e saxícola (Sipman et al. 2009). Em costões rochosos, no entanto, é uma espécie rara, sendo encontrada em locais protegidos, parcialmente ensolarados e próximos à vegetação arbustiva.

Espécimes examinados - BRASIL. Santa Catarina: São Francisco do Sul, Morro da Enseada, 05/V/2008, E. 
Gumboski 248, (UPCB), ibid, 13/V/2008, E. Gumboski 409, 421 (UPCB), ibid, 04/IX/2009, E. Gumboski 1665 (UPCB). Florianópolis, Praia dos Ingleses, 05/II/2011, S. Eliasaro 4992 (UPCB).

\section{Hypotrachyna osseoalba (Vain.) Y.S. Park \& Hale, Taxon} 38(1): 88. 1989.

Parmelia osseoalba Vain., Ann. bot. Soc. Zool.-Bot. fenn. Vanamo 1(no. 3): 39. 1921.

Fig. 3A-B

Talo laciniado, adnato, $3,0-11,0 \mathrm{~cm}$ de diâmetro, subcoriáceo, acinzentado, quebradiço. Lacínias de contíguas a subimbricadas, sublineares, $0,5-1,5 \mathrm{~mm}$ de largura, ramificação subdicotômica, margem lisa, inteira, de plana a involuta quando apresenta pústulas, ápice truncado, lacínulas e cílios ausentes. Superfície superior brilhosa, de inteira a raramente com fissuras irregulares, de lisa a variavelmente pustulada-sorediada; máculas e pruína ausentes. Pústulas de laminais a submarginais, capitadas, às vezes com aspecto dactilóide, rompendo-se parcialmente originando sorédios granulares, tornando-se coalescentes quando localizadas sobre as dobras do talo. Medula branca, às vezes com manchas de pigmento alaranjado $\mathrm{K}$ - nas pústulas. Superfície inferior negra, de lisa a pouco rugosa; margem estreita, até $0,5 \mathrm{~mm}$ de largura, de negra a marrom, papilada e densamente rizinada; rizinas de frequentes a abundantes, de ramificação principalmente dicotômica, raramente simples, com distribuição homogênea, negras, $0,2-1,5 \times 0,03-0,08 \mathrm{~mm}$. Apotécios ausentes. Picnídios laminais; conídios ausentes.

Química - Teste de coloração: córtex superior K-, UV+ amarelo (liquexantona); medula $\mathrm{K}+$ amarelo $\rightarrow$ pardo, $\mathrm{C}-$, KC-, UV-. CCD: liquexantona (córtex superior), ácidos colensóico, 4-O-metilfisódico, livídico, norcolensóico e duas substâncias não identificadas com $\mathrm{Rf}_{\mathrm{C}} \approx 11$ e 38 (medula). Distribuição - África (Swinscow \& Krog 1988), América do Norte, America Central, América do Sul, [Hale 1975, como Hypotrachyna formosana (Zahlbr.) Hale], Ásia (Hale 1975, como H. formosana) e Oceania (Elix 1994b). Na América do Sul: Brasil, Chile, Peru e Venezuela (Hale 1975, como H. formosana). No Brasil: MS (Sipman et al. 2009), PA (Brako et al. 1985, como H. formosana), PR (Eliasaro et al. 1998), RJ (Hale 1975), RS (Osorio \& Fleig 1990), SP (Marcelli 1991, como H. formosana). Este é o primeiro registro para SC.

Comentários - Hypotrachyna osseoalba é caracterizada pelo talo laciniado, pustulado-sorediado, pelo córtex superior com liquexantona e pela medula com ácidos do grupo livídico-colensóico.

Hypotrachyna subformosana Elix, T. H. Nash \& Sipman apresenta os mesmos compostos, mas difere por possuir sorédios farinhosos originados de sorais capitados subapicais (Sipman et al. 2009), ao passo que em H. osseoalba os sorédios são granulares e originam-se de pústulas laminais.

Hypotrachyna protoformosana Elix, T. H. Nash \& Sipman é morfologicamente muito similar por possuir lobos sublineares, de 0,5-3,0 mm de largura e superfície superior pustulada, eventualmente originando sorédios. No entanto, distingui-se na química medular, possuindo ácido protocetrárico como um dos principais metabólitos secundários (Sipman et al. 2009).

Esta espécie ocorre entre 500 a $2.700 \mathrm{~m}$ de altitude, geralmente como epífitas em áreas abertas (Sipman et al. 2009). Em costões rochosos, é rara, podendo ser encontrada próxima a vegetação arbustiva entremeada por briófitas.

Espécimes examinados - BRASIL. Santa Catarina: São Francisco do Sul, Morro da Enseada, 04/IX/2009, E. Gumboski 1667, 1670 (UPCB); ibid, 24/IX/2011, E. Gumboski 2585 (UPCB).

\section{Parmotrema dactylosum Fleig, Mycotaxon 71:200. 1999.} Fig. 4A-B

Talo lobado, adnato, 6,0-9,0 cm de diâmetro, membranáceo, de cinza-esverdeado a esbranquiçado. Lobos subimbricados, 4,0-8,0 $\mathrm{mm}$ de largura, ramificação irregular, margem lisa, inteira, sinuosa, delineada de marrom, de plana a ascendente e involuta, ápice rotundo, lacínulas e cílios ausentes. Superfície superior brilhosa, pouco fissurada, às vezes frágil descamando e expondo a medula, de lisa a rugosa em direção ao centro, frequentemente muito pustulada; máculas de ausentes a presentes em raros lobos, quando presentes nítidas ocorrendo em alguns lobos jovens, efiguradas e laminais; pruína ausente. Pústulas abundantes, aglomeradas, laminais, de capitadas a dactilóides, com a superfície lisa, em geral permanecendo intactas, mas raramente quando se rompem originam sorédios, os quais podem ou não ocorrer esparsos pelo talo. Medula branca. Superfície inferior negra, rugosa, moderadamente rizinada margem 1,0-4,0 $\mathrm{mm}$ de largura, de marrom clara a escura, de lisa a rugosa, errizinada a, rizinas simples, esparsas, de negras a raramente marrom claras, $0,2-0,8 \times 0,08-0,10 \mathrm{~mm}$. Apotécios de freqüentes a ausentes, quando presentes, submarginais, sésseis, côncavos, com a margem pustulada, disco até $5,0 \mathrm{~mm}$, imperfurado, marrom; ascósporos elipsóides, 15,0-17,0 × $7,0-8,0 \mu \mathrm{m}$. Picnídios raros, de laminais a submarginais; conídios bifusiformes, 6,0-7,5 × 1,0 $\mu \mathrm{m}$.

Química - Testes de coloração: córtex superior $\mathrm{K}+$ amarelo claro, UV-; medula K+ amarelo, C-, KC+ rosado, UV-. CCD: atranorina (córtex superior), norlobaridona e um ácido graxo não identificado com $\mathrm{Rf}_{\mathrm{C}} \approx 1$ (medula).

Distribuição - Brasil: RS (Fleig 1999). Este é o primeiro registro para SC.

Comentários - No protólogo de $P$. dactylosum, Fleig (1999) a caracteriza por possuir dáctilos marginais e laminais, às vezes densos na área central, simples ou esparsamente ramificados, que podem romper e expor a medula ou formar pústulas que originam sorédios granulares, pelos conídios de sublageniformes a pouco bifusiformes, com $5,0-7,0 \mu \mathrm{m}$ de comprimento e pela medula negativa em todos os testes de coloração, com ácidos caperático e graxos não identificados. 

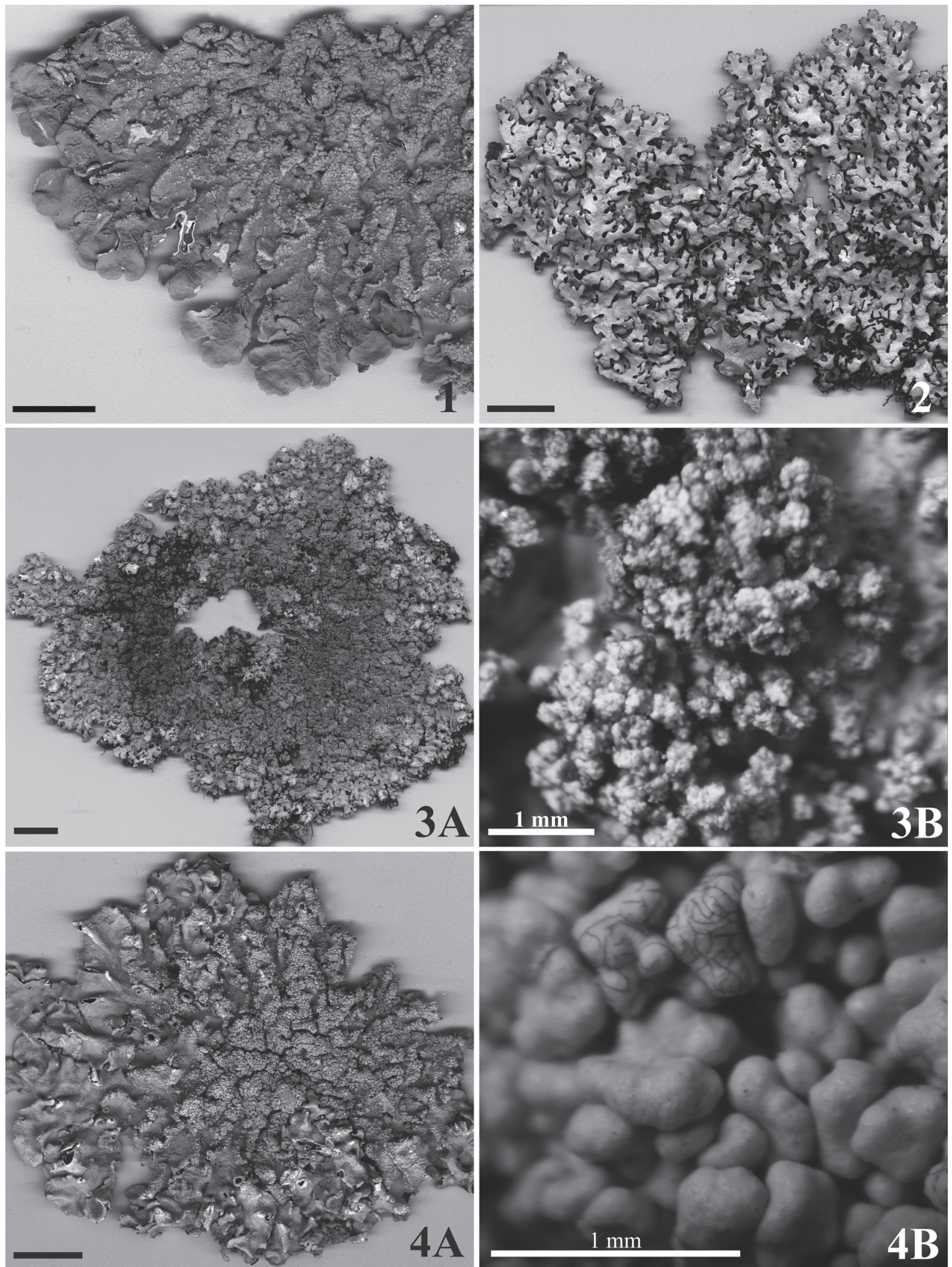

Figura 1-4. 1. Canoparmelia texana (Tuck.) Elix \& Hale (E. Gumboski \& F. Beilke 1747). 2. Hypotrachyna livida (Taylor) Hale (E. Gumboski 1665). 3. Hypotrachyna osseoalba (Vain.) Y. S. Park \& Hale. A. Aspecto geral. B. Detalhe (E. Gumboski 1667). 4. Parmotrema dactylosum Fleig. A. Aspecto geral. B. Detalhe (S. Eliasaro 4988). Escalas $=1 \mathrm{~cm}$ (exceto quando indicado). 
No mesmo trabalho Fleig (1999) publicou Parmotrema dissimile Fleig e a diferenciou de P. dactylosum principalmente por possuir medula $\mathrm{KC}+$ rosa com norlobaridona $\mathrm{e}$ loxodina, além de formar conídios sublageniformes.

Nas análises dos tipos de P. dactylosum (holótipo: $M$. Fleig 4486 ICN!) e de P. dissimile (holótipo: M. Fleig 6209 ICN! e parátipo: M. Fleig 6212 ICN!) observamos que em ambas a medula é KC+ rosa, e foram encontrados os mesmos compostos em CCD: atranorina, norlobaridona e um ácido graxo não identificado com $\mathrm{Rf}_{\mathrm{C}} \approx 1$, os quais também foram encontrados nos exemplares da área de estudo. Observamos também diferenças nas pústulas, enquanto em $P$. dactylosum são lisas (Fig. 4B), em $P$. dissimile possuem a superfície granulosa (Fig. 5B). Os exemplares da área de estudo têm a mesma morfologia do holótipo de P. dactylosum.

Parmotrema dactylosum pode ser facilmente reconhecida por ser a única espécie eciliada com pústulas intactas e lisas encontrada na área de estudo, frequente tanto nos costões rochosos quanto em pedras isoladas a beira mar principalmente na ilha de Santa Catarina, em locais protegidos, porém ensolarados.

Espécimes examinados - BRASIL. Santa Catarina: Governador Celso Ramos, Praia do Sicial, 02/IV/2011, A. Gerlach 665b (UPCB). Florianópolis, Praia dos Ingleses, 05/II/2011, S. Eliasaro 4988, 4995 (UPCB); ibid, Costão do Santinho, 17/IV/2010, A. Gerlach, E. Gumboski \& L. Oliveira 230 (UPCB); ibid, Barra da Lagoa, 17/IV/2010, A. Gerlach, E. Gumboski \& L. Oliveira 243 (UPCB); ibid, Praia do Gravatá, 06/IX/2010, A. Gerlach 380a, 404 (UPCB). Palhoça, Parque Estadual da Serra do Tabuleiro, Praia da Pinheira, 01/IX/2010, A. Gerlach 352, 355b (UPCB).

Espécimes adicionais examinados - Parmotrema dissimile Fleig. BRASIL. Paraná: Ponta Grossa, Vila Velha, saxícola, 05/II/1994, M. Fleig 6209 (holótipo: ICN), ibid, M. Fleig 6212 (parátipo: ICN).

5. Parmotrema endosulphureum (Hillmann) Hale, Phytologia 28(4): 33. 1974.

Parmelia tinctoria var. endosulphurea Hillmann, Repert. Sp. Nov. Fedde 48: 8. 1940.

Fig. 6

Talo lobado, frouxo-adnato, 6,0-16,0 cm de diâmetro, de subcoriáceo a coriáceo, de cinza amarronzado a esverdeado. Lobos de contíguos a subimbricados, 4,0-10,0 mm de largura, ramificação irregular, margem em geral lisa, às vezes isidiada, inteira, delineada de marrom, ascendente e involuta, ápice rotundo, lacínulas e cílios ausentes. Superfície superior opaca, contínua, de lisa a pouco rugosa no centro do talo, variavelmente isidiada principalmente na área central; máculas geralmente ausentes, quando presentes efiguradas e localizadas no ápice de alguns lobos jovens; pruína ausente. Isídios laminais, de isolados a densamente agrupados sobre as dobras do talo, às vezes localizados nas margens dos lobos, de cilíndricos a raramente granulares, de simples a frequentemente pouco ramificados, até $0,5 \times$ $0,1 \mathrm{~mm}$, ápice eciliado, marrom, em geral intactos, às vezes quebrados. Medula de amarelo escuro a claro em algumas áreas. Superfície inferior negra, de lisa a pouco rugosa, rizinada; margem ampla, 2,0-6,0 $\mathrm{mm}$ de largura, marrom clara, lisa, errizinada; rizinas escassas, simples, agrupadas, negras, $0,2-1,0 \times 0,08-0,1 \mathrm{~mm}$. Apotécios ausentes. Picní-

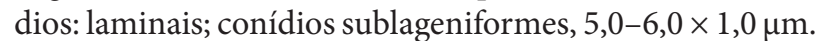

Química - Testes de coloração: córtex superior $\mathrm{K}+$ amarelo, UV-; medula K+ alaranjado, C-, KC-, UV-. CCD: atranorina e eumitrina.

Distribuição - África, América do Norte, América Central, América do Sul e Ásia (Hale 1965). Na América do Sul: Brasil, Chile, Colômbia e Venezuela (Hale 1965). No Brasil: BA (Hale 1965), PR (Eliasaro 2006), RJ, RS e SP (Hale 1965). Este é o primeiro registro para SC.

Comentários - Parmotrema endosulphureum é caracterizada por possuir lobos largos com margens eciliadas, isídios cilíndricos e medula amarela enxofre.

Parmotrema aurantiacoparvum Sipman, P. enteroxanthum Hale e P.sulphuratum (Nees \& Flotow) Hale, também isidiadas e com medula pigmentada, podem ser diferenciadas por serem ciliadas (Hale 1974; 1977; Sipman \& Aubel 1992, Benatti \& Marcelli 2009a), e por apresentarem outros compostos medulares, respectivamente uma antraquinona (Sipman \& Aubel 1992, Benatti \& Marcelli 2009a), ácido salazínico e possivelmente uma entoteína (Hale 1977) e ácido vulpínico (Hale 1974, Benatti \& Marcelli 2009a).

Parmotrema flavomedullosum Hale é similar por possuir lobos largos e medula amarela (Hale 1974; Kurokawa 1974), entretanto, é pustulada (Kurokawa 1974).

Os exemplares analisados apresentaram isídios de até 0,5 $\mathrm{mm}$ de comprimento, semelhantes aos descritos por Benatti \& Marcelli (2009a), mas bem menores quando comparado aos isídios descritos por Hale (1965), os quais medem até 3,0 mm de comprimento.

Parmotrema endosulphureum é frequentemente encontrada em costões rochosos catarinenses em locais protegidos e parcialmente ensolarados, às vezes se desenvolvendo próximo a P. tinctorum (Nyl.) Hale. Estas espécies podem ser confundidas em campo, pelo aspecto geral do talo, contudo, P. tinctorum possui medula totalmente branca. Parmotrema endosulphureum foi citada por Benatti \& Marcelli (2009a) em rochas úmidas graníticas a beira-mar no litoral de São Paulo.

Espécimes examinados - BRASIL. Santa Catarina: São Francisco do Sul, Morro da Enseada, 19/VI/2008, E. Gumboski 552 (UPCB). Governador Celso Ramos, Praia do Sicial, 02/IV/2011, A. Gerlach 671 (UPCB). Bombinhas, Praia Retiro dos Padres, 07/XII/2010, A. Gerlach 542, 555b, 557, 559, 563 (UPCB). Laguna, Praia da Galheta, 18/II/2010, E. Gumboski \& F. Beilke 1771 (UPCB).

6. Parmotrema mordenii (Hale) Hale, Phytologia 28(4): 337. 1974. 
Parmelia mordenii Hale, Smithson. Contr. bot. 4: 19. 1971. Fig. 7

Talo lobado, adnato, 6,0-14,0 cm de diâmetro, membranáceo, acinzentado. Lobos de contíguos a subimbricados, 4,5-8,5 mm de largura, ramificação irregular, margem de lisa nas bordas do talo a frequentemente sorediada em direção ao centro, de inteira nos lobos mais jovens a crenada, delineada de marrom, tornando-se sinuosa, ascendente e involuta quando sorediada, ápice rotundo, lacínulas e cílios ausentes. Superfície superior brilhosa, de contínua a irregularmente fissurada nos lobos mais velhos, de lisa a bastante rugosa no centro, raramente sorediada; máculas e pruína ausentes. Sorais de marginais lineares a submarginais, em alguns talos alcançam a lâmina e possuem forma orbicular, podendo ou não se tornar coalescente, raramente possuindo aspecto pustular; sorédios subgranulares. Medula branca. Superfície inferior negra, de lisa a rugosa, rizinada, margem ampla, 1,0-6,5 mm de largura, de marrom clara a raramente branca sob lobos sorediados (A. Gerlach 349a e E. Gumboski \& F. Beilke 1746), lisa, errizinada; rizinas escassas, de simples a irregularmente furcadas, esparsas, de negras a castanhas quando próximo às margens, até 0,5 $\times 0,03-0,10 \mathrm{~mm}$. Apotécios de freqüentes a ausentes em alguns talos, quando presentes submarginais, sésseis, de planos a pouco cupuliformes, margem sorediada, disco até 5,0 cm, imperfurado, marrom; ascósporos elipsóides, $(14,0-)$ 15,0-20,0 × (5,0-) 7,5-10,0 $\mu \mathrm{m}$. Picnídios raros, submarginais; conídios ausentes.

Química - Testes de coloração: córtex superior K+ amarelo, UV-; medula K+ lentamente amarelo claro a escuro, C-, KC--, UV-. CCD: atranorina (córtex superior e medula) e um ácido graxo não identificado com $\mathrm{Rf}_{\mathrm{C}} \approx 17$, UV+ azul após revelação (medula).

Distribuição - África (Winnem 1975), América do Norte, América Central (Hale 1971) e América do Sul (López-Figueiras 1986). Na América do Sul: Brasil (Marcelli 1991) e Venezuela (López-Figueiras 1986). No Brasil: RS (Spielmann \& Marcelli 2009), SP (Marcelli 1991). Este é o primeiro registro para o $\mathrm{PR}$ e SC.

Comentários - Parmotrema mordenii se caracteriza pelo talo saxícola, membranáceo, com as margens dos lobos sorediadas, pela superfície inferior negra com rizinas escassas e pela presença de atranorina medular (medula K+ amarelo).

Parmotrema praesorediosum (Nyl.) Hale é morfologicamente muito similar a P. mordenii, sendo de acordo com Hale (1971), diferenciada desta pelo talo corticícola, reação medular K- e pelos sorédios mais finos produzidos em sorais lineares crescentes ou labriformes.

Krog \& Swinscow (1981), ao estudarem exemplares africanos, sinonimizaram $P$. mordenii a $P$. praesorediosum por terem observado exemplares corticícolas e saxícolas com medula $\mathrm{K}+$ amarelada e que não apresentavam as diferenças morfológicas mencionadas por Hale (1971).

Porém, de acordo com Nash \& Elix (2002b), P. praesorediosum é diferenciada pelos sorais de lineares a crescentes, de marginais a submarginais e pela medula com os ácidos protopraesorediósico e praesorediósico, enquanto P. mordenii possui sorais de lineares a orbiculares, de marginais a laminais e os ácidos caperático e protoliquesterínico.

Marcelli \& Benatti (2010a), no entanto, ao analisarem exemplares do litoral de São Paulo, além de as diferenciarem pelo hábito e reação medular encontraram os ácidos praesorediósico e caperático em ambas as espécies. Também apontam que os talos de $P$. praesorediosum tendem a possuir sorais marginais labriformes ou crescentes, com sorédios mais finos e acrescentam que a margem inferior varia de marrom a branca, negra, creme ou variegada quando sob lobos sorediados enquanto, que em $P$. mordenii a margem é sempre marrom.

Embora Marcelli \& Benatti (2010a) citem os ácidos graxos caperático, protoliquesterínico, praesorediósico e protopraesorediósico para $P$. mordenii, nos materiais cromatografados da área de estudo, tais ácidos não foram encontrados, mas o hábito saxícola e a reação medular K+ amarelo foram observados em todos os exemplares.

Parmotrema mordenii é a espécie mais freqüente nos costões rochosos. Foi encontrada em locais protegidos do spray marinho, amplamente distribuída tanto sob sol quanto na sombra, às vezes em locais úmidos com escorrimento da água da chuva, ou crescendo junto a briófitas.

Espécimes selecionados examinados - BRASIL. Paraná: Guaratuba, Praia de Brejatuba, 24/IX/2011, E. Gumboski \& F. Beilke 2590 (UPCB). Santa Catarina: São Francisco do Sul, Morro da Enseada, 19/III/2008, E. Gumboski 44 (UPCB). Governador Celso Ramos, Praia do Sicial, 01/IV/2011, A. Gerlach 650 (UPCB). Florianópolis, Praia do Matadeiro, 18/IV/2010, A. Gerlach, E. Gumboski \& L. Oliveira 266 (UPCB). Palhoça, Parque Estadual da Serra do Tabuleiro, Ponta dos Papagaios, 31/VIII/2010, A. Gerlach 337 (UPCB); ibid, Praia da Pinheira, 01/IX/2010, A. Gerlach 349 (UPCB). Bombinhas, Retiro dos Padres, 07/XII/2010, A. Gerlach 548 (UPCB). Imbituba, Barra de Ibiraquera, 30/ IX/2010, A. Gerlach 476 (UPCB); ibid, Praia de Itapirubá, 19/II/2010, E. Gumboski \& F. Beilke 1746 (UPCB).

7. Parmotrema tinctorum (Nyl.) Hale, Phytologia 28: 339. 1974.

Parmelia tinctorum Nyl., Flora, Jena 55: 547. 1872.

Fig. 8

Talo lobado, frouxo-adnato, $6,0-14,0 \mathrm{~cm}$ de diâmetro, coriáceo, cinza amarronzado. Lobos subimbricados, 4,0-16,0 mm de largura, ramificação irregular, margem de lisa a isidiada, inteira, delineada de marrom, ascendente, lóbulos quando presentes laminais, por entre as aglomerações de isídios, ápice rotundo, lacínulas e cílios ausentes. Superfície superior opaca, de inteira a pouco fissurada, lisa, de moderada a densamente isidiada; máculas ausentes ou quando presentes muito tênues, puntiformes, laminais; pruína ausente. Isídios iniciando sobre as fissuras do córtex e espalhando-se por quase toda a lâmina e sobre as dobras do talo, presentes também nas margens de alguns lobos, 
predominantemente cilíndricos na maioria dos talos, variando para granulares, simples a pouco ramificados quando isolados, frequentemente formando aglomerados coralóides, de 0,2-1,5 × 0,02-0,10 (-0,30) mm, ápice eciliado, de marrom a raramente negro, geralmente intacto, alguns quebrados ou muito raramente descamando e originando fragmentos corticados. Medula branca. Superfície inferior negra, de lisa a pouco rugosa, rizinada, margem ampla, $3,0-9,0 \mathrm{~mm}$ de largura, marrom, de lisa a pouco rugosa, errizinada ou com algumas poucas rizinas marrons; rizinas escassas, de simples a furcadas, esparsas, negras, $0,1-2,0 \times$ 0,08-0,20 mm. Apotécios ausentes. Picnídios submarginais; conídios filiformes, 8,0-12,0 × 1,0 $\mu \mathrm{m}$.

Química - Testes de coloração: córtex superior $\mathrm{K}+$ amarelo, UV-; medula $\mathrm{K}-, \mathrm{C}+$ rosa, $\mathrm{KC}+$ rosa, UV-. CCD e Microcristalografia: atranorina (córtex superior) e ácido lecanórico (medula).

Distribuição - África, América do Norte, América Central, América do Sul, Ásia (Hale 1965), Europa (Carvalho et al. 2008) e Oceania (Hale 1965). Na América do Sul: Argentina, Brasil, Colômbia, Equador, Guianas, Paraguai, Peru (Hale 1965), Uruguai (Osorio 1972) e Venezuela (Hale 1965). No Brasil: MG (Hale 1965), MS (Fleig \& Riquelme 1991), MT (Hale 1965), PA (Brako et al. 1985), PR (Osorio 1977), RJ (Hale 1965), RS (Osorio et al. 1981), SC (Osorio 1997), SP (Hale 1965).

Comentários - Parmotrema tinctorum é facilmente reconhecida por possuir lobos largos, superfície superior isidiada e ácido lecanórico na medula.

Parmotrema pseudotinctorum diferencia-se por possuir isídios designados por Hale (1965) como inflados, de até 0,5 $\mathrm{mm}$ de altura e com $0,2-0,3 \mathrm{~mm}$ de largura. Nos exemplares A.Gerlach 567 e 590, os isídios são predominantemente mais curtos e espessos $(0,2-0,3 \times 0,1-0,3 \mathrm{~mm})$. Porém, na maioria dos exemplares analisados os isídios que predominam são cilíndricos, longos $(0,5-1,5 \mathrm{~mm})$ e finos $(0,02-0,10 \mathrm{~mm})$ e em alguns pontos do mesmo talo ocorrem isídios mais curtos $(0,2-0,3 \mathrm{~mm})$ e espessos $(0,1-0,3 \mathrm{~mm})$, deste modo não consideramos como um caráter de importância taxonômica.

Parmotrema eitenii Marcelli \& Benatti é muito similar a $P$. tinctorum, no entanto forma sorais marginais lineares interrompidos a irregulares, menos frequentemente os sorédios são formados em cristas talinas e gradualmente se aglomeram em estruturas com aspecto granular, pustular ou isidióide, os quais podem se tornar corticados, mas não formando isídios verdadeiros (Marcelli et al. 2007, Benatti \& Marcelli 2009b). O exemplar A. Gerlach 357 apresenta pequenos isídios cilíndricos agrupados que descamam a partir do ápice formando pequenos fragmentos similares a sorédios, mas não apresentam sorais.

Parmotrema tinctorum foi anteriormente mencionada para costões rochosos no município de Torres, Rio Grande do Sul (Osorio \& Fleig 1984b). Esta espécie é frequente ao longo dos costões rochosos catarinenses, podendo ser encontrada em locais protegidos do spray marinho e parcialmente ensolarados.
Espécimes selecionados examinados - BRASIL. Santa Catarina: São Francisco do Sul, Morro da Enseada, 19/ VI/2008, E. Gumboski 514 (UPCB). Governador Celso Ramos, Praia do Sicial, A. Gerlach 667 (UPCB). Palhoça, Parque Estadual do Tabuleiro, Praia da Pinheira, 01/IX/2010, A. Gerlach 357 (UPCB). Bombinhas, Praia da Sepultura, 07/XII/2010, A. Gerlach 519 (UPCB); ibid, Praia de Quatro Ilhas, 07/XII/2010, A. Gerlach 567, 590 (UPCB). Imbituba, Barra de Ibiraquera, 30/IX/2010, A. Gerlach 475 (UPCB).

\section{Pseudoparmelia cubensis (Nyl.) Elix \& T.H. Nash,} Bryologist 100(4): 490. 1997.

Parmelia cubensis Nyl., Flora, Jena 68: 611. 1885.

Fig. 9

Talo lobado, adnato, 8,0-13,0 cm de diâmetro, coriáceo, de verde claro a marrom acinzentado. Lobos imbricados, (1,6-) 2,0-7,0 mm de largura, ramificação irregular, margem lisa, crenada, sinuosa, às vezes delineada de marrom, de plana a pouco ascendente, ápice rotundo, lacínulas e cílios ausentes. Superfície superior opaca, inteira, lisa, às vezes escrobiculada nos lobos mais jovens; máculas de tênues a nítidas em alguns lobos jovens, efiguradas, laminais; pruína ausente. Propágulos vegetativos ausentes. Medula amarela clara. Superfície inferior marrom clara, lisa, escassa e moderadamente rizinada, margem indistinta do centro, parcialmente rizinada; rizinas de simples a bifurcadas ou irregularmente furcadas nos ápices, esparsas, de concolores a negras, $0,2-0,8 \times 0,03-0,10 \mathrm{~mm}$. Apotécios abundantes, laminais, sésseis, côncavos, margem crenada, lisa, disco até $2,0 \mathrm{~mm}$, imperfurado, de marrom avermelhado a negro; ascósporos ovóides, 6,0-9,0 × 6,0-7,0 $\mu \mathrm{m}$. Picnídios raros, submarginais; conídios poucos, bifusiformes, 7,0-9,0 × 1,0 $\mu \mathrm{m}$.

Química - Testes de coloração: córtex superior $\mathrm{K}+$ amarelo, UV-; medula $\mathrm{K}+$ amarelo $\rightarrow$ alaranjado, $\mathrm{C}-$, KC-, UV-. CCD: atranorina (córtex superior), ácidos estíctico, secalônico A e provavelmente conestíctico (medula).

Distribuição - América do Norte, América Central, América do Sul (Elix \& Nash 1997). Na América do Sul: Brasil, Equador e Venezuela (Elix \& Nash 1997). No Brasil: MT, PA, SC e SP (Elix \& Nash 1997). Este é o primeiro registro para o $P R$.

Comentários - Pseudoparmelia cubensis é caracterizada por não produzir propágulos vegetativos, pelos lobos largos (2,0-7,0 mm), medula com ácido estíctico, ascósporos ovóides, superfície inferior marrom e conídios de 7,0-9,0 $\mu \mathrm{m}$ de comprimento.

Pseudoparmelia brakoana Elix \& Nash é semelhante a P. cubensis pela ausência de propágulos e pela presença dos ácidos do grupo estíctico na medula (Elix \& Nash 1997), mas possui lobos mais estreitos, de 1,0-3,0 mm e conídios maiores, 9,0-13,0 $\mu \mathrm{m}$ de comprimento (Elix \& Nash 1997).

É uma espécie rara nos costões rochosos do Paraná e Santa Catarina, sendo encontrada em áreas protegidas do spray marinho, sempre em locais sombreados e úmidos. Este é o primeiro registro da espécie sobre rocha. 

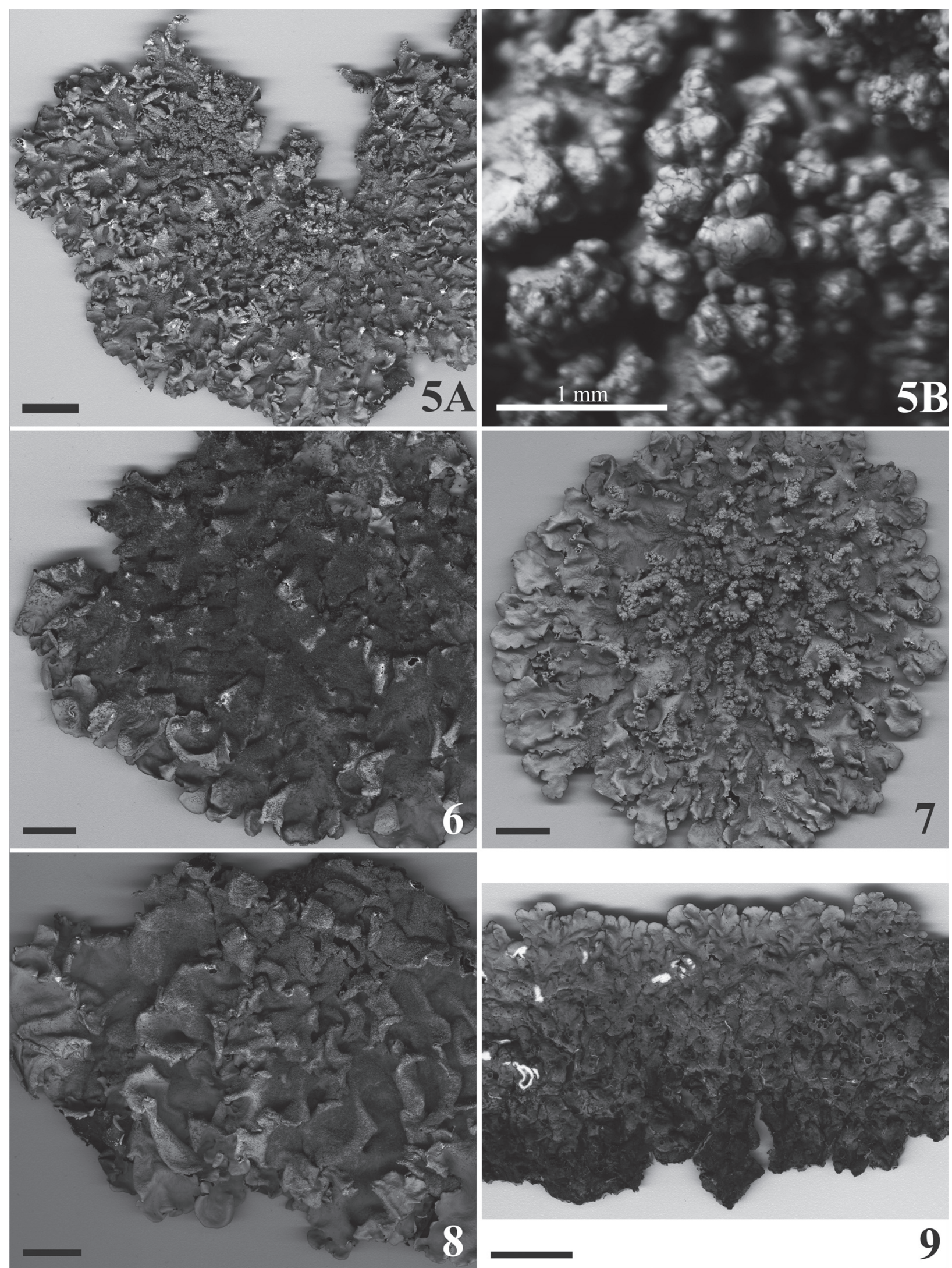

Figura 5-9. 5. Parmotrema dissimile Fleig. A. Aspecto geral. B. Detalhe (holótipo: Fleig 6209). 6. Parmotrema endosulphureum (Hillmann) Hale (A. Gerlach 671). 7. Parmotrema mordenii (Hale) Hale (A. Gerlach 650). 8. Parmotrema tinctorum (Despr. ex Nyl.) Hale (A. Gerlach 475). 9. Pseudoparmelia cubensis (Nyl.) Elix \& T. H. Nash (E. Gumboski 553). Escalas $=1 \mathrm{~cm}$ (exceto quando indicado). 
Espécimes examinados - BRASIL. Paraná: Paranaguá, Parque Estadual da Ilha do Mel, 06/II/2010, E. Gumboski 1790 (UPCB). Guaratuba, Praia de Brejatuba, 02/IX/2011, E. Gumboski \& F. Beilke 2586 (UPCB). Santa Catarina: São Francisco do Sul, Morro da Enseada, 19/ VI/2008, E. Gumboski 553, 554, 555 (UPCB).

\section{Xanthoparmelia catarinae Hale, Mycotaxon 34(2): 543. 1989.}

Fig. 10, 11, 12

Talo de sublaciniado e adnato nas margens a laciniado e frouxo-adnato no centro do talo, 5,0-12,0 cm de diâmetro, subcoriáceo, amarelo-esverdeado. Sublacínias subimbricadas, subirregulares, 1,5-3,5 mm de largura, ramificação irregular, margem lisa, inteira, plana, ápice subtruncado; lacínias imbricadas, sublineares, 0,5-1,0 $\mathrm{mm}$ de largura, ramificação subdicotômica, margem lisa, inteira e pouco involuta, ápice truncado; lacínulas e cílios ausentes. Superfície superior: brilhosa, inteira, de lisa a isidiada; máculas e pruína ausentes. Isídios laminais e na margem dos apotécios, inicialmente subglobosos tornando-se cilíndricos, de simples a pouco ramificados, raramente coralóides, $0,3-1,0 \times 0,1-0,3 \mathrm{~mm}$, ápice eciliado, marrom escuro, intacto. Medula: branca. Superfície inferior: negra, de lisa a pouco rugosa; margem até $1,0 \mathrm{~mm}$ de largura, marrom escuro, lisa, errizinada; rizinas escassas, simples, esparsas, negras, $0,1-0,5 \times 0,08-0,1 \mathrm{~mm}$. Apotécios: presentes ou ausentes, laminais, sésseis, de planos a côncavos, margem de lisa a isidiada, disco até $6,0 \mathrm{~mm}$, imperfurado, marrom; ascósporos ausentes. Picnídios: laminais; conídios bifusiformes, 6,0-7,0 × 1,0 $\mu \mathrm{m}$.

Química - Testes de coloração: córtex superior K-, UV-; medula $\mathrm{K}+$ amarelo $\rightarrow$ lentamente alaranjado, $\mathrm{C}-$, KC- UV-. CCD: ácidos úsnico (córtex superior), estíctico, conestíctico e norestíctico (medula). Distribuição - América do Sul. Brasil: BA (Nash et al. 1995), RS e SC (Hale 1989). Este é o primeiro registro para o PR.

Comentários - A principal característica de Xanthoparmelia catarinae é a diferenciação morfológica entre as margens e o centro do talo. Enquanto as margens são bastante aderidas ao substrato, subimbricadas e com sublacínias de até 3,5 $\mathrm{mm}$ de largura, o centro é formado por lacínias frouxo-adnatas, imbricadas e mais estreitas, de até 1,0 $\mathrm{mm}$. Caracteriza-se também por possuir isídios cilíndricos, superfície inferior negra e ácidos medulares do complexo estíctico.

Esta espécie é bastante similar a Xanthoparmelia conspersa (Ach.) Hale, que também é isidiada, com a superfície inferior negra e ácidos do grupo estíctico (Hale 1990; Nash et al. 1995), porém não apresenta diferenciação entre as margens e o centro do talo e as lacínias são sempre frouxo-adnatas (Hale 1990; Nash et al. 1995). Assim como Nash et al. (1995), chamamos a atenção para o cuidado na coleta e análise de exemplares desta espécie pois em geral a porção central é mais facilmente destacada e caso seja a única parte do talo coletada poderá ser confundida com $X$. conspersa.
Xanthoparmelia catarinae ocorre predominantemente em ambientes costeiros (Nash et al. 1995), sendo o holótipo proveniente de rocha granítica no município de Florianópolis. Embora esta seja a primeira citação sobre costões rochosos, é a espécie do gênero melhor representada neste ambiente no Paraná e em Santa Catarina. É facilmente encontrada formando grandes manchas verde-amareladas em locais ensolarados e pode ser reconhecida facilmente em campo pelo talo diferenciado, com margens adnatas e o centro formando um tapete de lacínias; além disso, foi a única espécie do gênero encontrada na área de estudo com a superfície inferior negra.

Espécimes selecionados examinados - BRASIL. Paraná: Paranaguá, Parque Estadual da Ilha do Mel, 28/ VIII/2009, S. Eliasaro 3163 (UPCB). Santa Catarina: São Francisco do Sul, Morro da Enseada, 19/VI/2008, E. Gumboski 420 (UPCB). Governador Celso Ramos, Praia do Sicial, 02/IV/2011, A. Gerlach 656 (UPCB). Florianópolis, Praia do Gravatá, 06/IX/2010, A. Gerlach 381a (UPCB); ibid, Praia dos Ingleses, 05/II/2011, S. Eliasaro 4994 (UPCB). Palhoça, Parque Estadual da Serra do Tabuleiro, Praia da Guarda do Embaú, 01/IX/2010, A. Gerlach 376 (UPCB). Bombinhas, Praia de Quatro Ilhas, 07/XII/2010, A. Gerlach 577 (UPCB).

10. Xanthoparmelia neopropaguloides Hale, Smithson. Contr. bot. 74: 157. 1990.

Parmelia stenophylloides var. propagulifera Vain., Acta Soc.

Faun. Fl. Fenn. 7(1): 62. 1890.

Fig. 13

Talo laciniado, fortemente aderido, 2,0 cm de diâmetro, ar eolado no centro, verde-amarelado. Lacínias contíguas, sublineares, $0,3-0,8 \mathrm{~mm}$ de largura, ramificação subdicotômica, margem lisa, inteira, plana, ápice truncado, lacínulas e cílios ausentes. Superfície superior brilhosa, de contínua a frequentemente com fissuras transversais, de lisa a esparsamente isidiada; máculas e pruína ausentes. Isídios escassos, laminais, de globosos a curto cilíndricos, simples, até $0,2 \times$ $0,2 \mathrm{~mm}$, ápice eciliado, marrom escuro e intacto. Medula branca. Superfície inferior marrom, moderadamente rizinada, rizinas simples, concolores, $0,2 \times 0,08 \mathrm{~mm}$, devido à forte adnação do talo outros caracteres não puderam ser observados. Apotécios e picnídios ausentes.

Química - Testes de coloração: córtex superior K-, UV-; medula K+ amarelo, C-, KC-, UV-. CCD: ácidos úsnico (córtex superior), estíctico e conestíctico (medula).

Distribuição - África, América Central e América do Sul (Hale 1990). Na América do Sul: Brasil, Guiana, Paraguai, Uruguai e Venezuela (Nash et al. 1995). No Brasil é citada para os estados de GO, MG, PR (Eliasaro \& Adler 2002), SC e SP (Nash et al. 1995).

Comentários - Xanthoparmelia neopropaguloides caracteriza-se pelo talo fortemente aderido, com lacínias estreitas, até $0,8 \mathrm{~mm}$, isídios globosos a curto cilíndricos, superfície inferior marrom e por possuir ácidos do grupo estíctico.

Xanthoparmelia plittii, que também ocorre na área de estudo, é similar, entretanto, possui lacínias mais largas, 
0,9-1,2 mm e com isídios cilíndricos maiores, $0,2-0,5(-1,0)$, simples a ramificados.

Xanthoparmelia neopropaguloides foi a espécie mais fortemente aderida ao substrato encontrada na área de estudo e várias tentativas de coleta resultaram em talos fragmentados. Por este motivo foi pouco amostrada, mas é abundante nos costões rochosos catarinenses, sendo encontrada formando grandes manchas verde-amareladas em platôs bem ensolarados.

Espécimes examinados - BRASIL. Santa Catarina: São Francisco do Sul, Morro da Enseada, E. Gumboski 2579 (UPCB). Imbituba, Barra de Ibiraquera, 30/IX/2010, A. Gerlach 485 (UPCB).

11. Xanthoparmelia plittii (Gyeln.) Hale, Phytologia 28: 488. 1974.

Parmelia plittii Gyeln., Reprium nov. Spec. Regni veg. 29: 287. 1931.

Fig. 14

Talo laciniado, adnato, $2,0-4,0 \mathrm{~cm}$ de diâmetro, amarelo-esverdeado. Lacínias subimbricadas, sublineares, 0,9-1,2 $\mathrm{mm}$ de largura, ramificação subdicotômica, margem lisa, inteira, plana, ápice truncado, lacínulas e cílios ausentes. Superfície superior brilhosa, inteira, de lisa a moderadamente isidiada; máculas e pruína ausentes. Isídios laminais, de subglobosos a cilíndricos, de simples a pouco ramificados, raramente coralóides, $0,2-0,5(-1,0) \times 0,08 \mathrm{~mm}$, ápice eciliado, marrom escuro, de intacto a quebrado. Medula branca. Superfície inferior marrom, lisa, rizinada, margem indistinta do centro; rizinas freqüentes, simples, esparsas, de concolores a negras, $0,1-0,5 \times 0,1-0,2 \mathrm{~mm}$. Apotécios de presentes em alguns talos a ausentes, quando presentes laminais, sésseis, planos, com margem de lisa a pouco isidiada, disco até 4,0 mm, imperfurado, marrom, ascósporos elipsóides, 8,0-10,0 $\times 5,0 \mu \mathrm{m}$. Picnídios laminais; conídios ausentes.

Química - Testes de coloração: córtex superior K-, UV-; medula K+ amarelo, C-, KC-, UV-. CCD: ácidos úsnico (córtex superior), estíctico, conestíctico e norestíctico (medula).

Distribuição - África, América do Norte (Hale 1964), América Central, América do Sul (Hale 1990) e Europa (Giordani et al. 2002). Na América do Sul: Argentina (Nash et al. 1995), Brasil, Colômbia, Paraguai, Uruguai e Venezuela (Hale 1990). No Brasil é citada para os estados de BA, MG, PB, PE (Nash et al. 1995), PR (Eliasaro \& Adler 2002), RJ, RS, SC e SP (Nash et al. 1995).

Comentários - Xanthoparmelia plittii caracteriza-se pelo talo adnato, com lacínias maiores que $0,8 \mathrm{~mm}$ de largura, isidios cilíndricos, superfície inferior marrom e com ácidos medulares do complexo estíctico.

Xanthoparmelia neopropaguloides, uma espécie similar e que também ocorre na área, diferencia-se de X. plittii pelas lacínias mais estreitas, $0,3-0,8 \mathrm{~mm}$ e pelo talo mais aderido ao substrato.

Xanthoparmelia plittii é frequente nos costões rochosos catarinenses, pode ser encontrada formando grandes man- chas verde-amareladas sobre rochas planas, sempre em locais ensolarados, junto a X. catarinae e X. neopropaguloides.

Espécimes examinados - BRASIL. Santa Catarina: São Francisco do Sul, Morro da Enseada, 19/VI/2008, E. Gumboski 459, 574 (UPCB); ibid, 24/IX/2011, E. Gumboski 2580 (UPCB). Florianópolis, Costão do Santinho, 17/ IV/2010, A. Gerlach, E. Gumboski \& L. Oliveira 237, 239, 270 (UPCB); ibid, Praia do Gravatá, 06/IX/2010, A. Gerlach 407 (UPCB). Bombinhas, Praia de Quatro Ilhas, 07/XII/2010, A. Gerlach 597 (UPCB).

12. Xanthoparmelia subramigera (Gyeln.) Hale, Phytologia 28: 489.1974.

Parmelia subramigera Gyeln. Fedde Repertorium Specierum Novarum Regni Vegetatilis 29: 273-291. 1931.

Fig. 15

Talo sublaciniado, de adnato a frouxo-adnato, 10,0-13,0 $\mathrm{cm}$ de diâmetro, subcoriáceo, amarelo-esverdeado. Lacínias de subimbricadas a pouco imbricadas no centro do talo, de subirregulares a sublineares, $1,0-5,5 \mathrm{~mm}$ de largura, ramificação irregular, margem lisa, de inteira a pouco crenada, delineada de marrom, planas, ápice de subtruncado a arredondado, lacínulas e cílios ausentes. Superfície superior brilhosa, de continua a irregularmente fissurada, de lisa a pouco rugosa em alguns talos, frequentemente isidiada; máculas tênues no ápice de alguns lobos mais jovens, de efiguradas a extensivas, pruína ausente. Isídios laminais, densos na maioria dos exemplares a quase imperceptíveis no exemplar E. Gumboski \& F. Beilke 1846, de subglobosos a principalmente cilíndricos, de simples a pouco ramificados, até $0,5 \times 0,08-0,20 \mathrm{~mm}$, ápice eciliado, marrom, de intacto a frequentemente quebrado. Medula branca. Superfície inferior marrom clara, lisa, frequentemente com a medula exposta, moderadamente rizinada, margem indistinta do centro, rizinas simples, esparsas, de concolores a negras, 0,1-0,7 × 0,03-0,20 mm. Apotécios ausentes. Picnídios laminais; conídios de sublageniformes a bifusiformes sutis, $5,0-8,0 \times 0,5-1,0 \mu \mathrm{m}$.

Química - Testes de coloração: córtex superior K-, UV-; medula $\mathrm{K}+$ marrom avermelhado, $\mathrm{C}-$, $\mathrm{KC}-$, UV-. CCD: ácidos úsnico (córtex superior), succinprotocetrárico e fumarprotocetrárico (medula).

Distribuição - África (Nash \& Elix 1987), América do Norte (Hale 1964), América Central, América do Sul (Hale 1990), Ásia (Hale 1990) e Europa (Carvalho et al. 2008). Na América do Sul: Brasil (Hale 1990), Chile (Nash et al. 1995), Colômbia (Hale 1990), Equador, Uruguai (Nash et al. 1995) e Venezuela (Hale 1990). No Brasil é citada para o Estado do RS (Fleig 1995). Este é o primeiro registro para os estados do PR e de SC.

Comentários - Xanthoparmelia subramigera caracteriza-se por possuir lacínias largas, isidios de subglobosos a cilíndricos de simples a pouco ramificados, superfície inferior marrom claro e presença medular dos ácidos fumarprotocetrárico e succinprotocetrárico. 

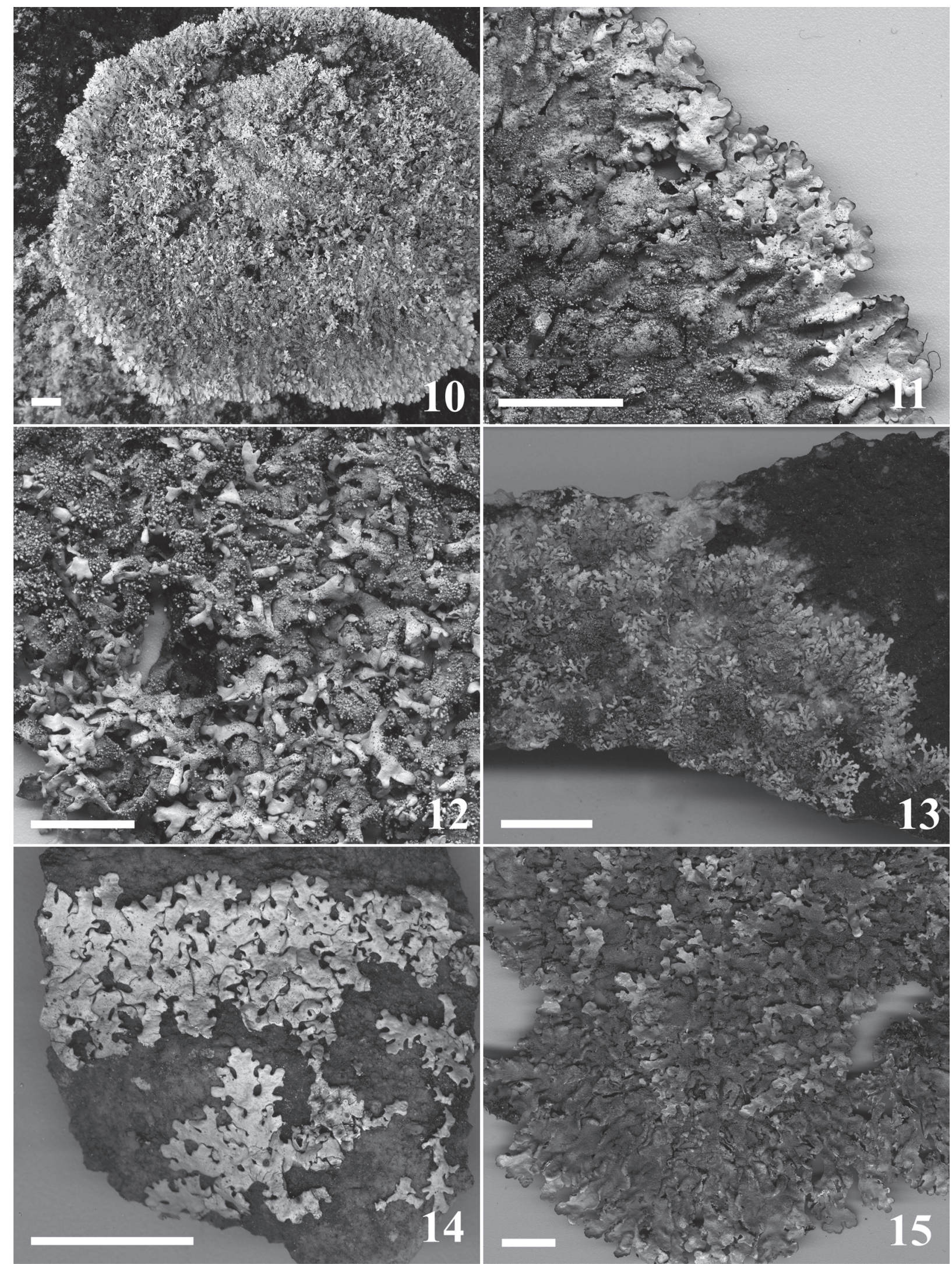

Figura 10-15. 10. Xanthoparmelia catarinae Hale em campo (A. Gerlach 656). 11. X. catarinae, margem do talo (A. Gerlach 365). 12. X. catarinae, centro do talo (A. Gerlach 656). 13. Xanthoparmelia neopropaguloides Hale (E. Gumboksi 2579). 14. Xanthoparmelia plittii (Gyeln.) Hale (A. Gerlach 237). 15. Xanthoparmelia subramigera (Gyeln.) Hale (A. Gerlach 660). Escalas $=1 \mathrm{~cm}$. 
Xanthoparmelia catarinae é a espécie da área de estudo que mais se aproxima de $X$. subramigera no aspecto geral do talo. Ambas são bem desenvolvidas, possuem sublacínias largas e lacinias imbricadas no centro do talo. No entanto, $X$. catarinae é facilmente diferenciada por possuir inferior negra e ácidos medulares do complexo estíctico.

O espécime E. Gumboski \& F. Beilke 1846 diferencia-se dos demais exemplares analisados de $X$. subramigera por apresentar lacínias com ápice bastante arredondado e isídios quase imperceptíveis, muito escassos. Porém, como compartilham as demais características morfológicas e químicas é mantido sob o nome de $X$. subramigera.

Xanthoparmelia hirosakiensis (Gyeln.) Kurok. é muito similar, foi considerada conspecífica de X. subramigera por Hale (1990), mas recentemente foi sustentada filogeneticamente como espécie distinta por Wang et al. (2008). Kurokawa (1989) diferenciou X. hirosakiensis de X. subramigera pela primeira possuir superfície inferior marrom mais escuro, isídios coralóides e presença dos ácidos fumarprotocetrárico e protocetrárico medulares.

Xanthoparmelia lopezii Nash \& Elix também é isidiada com superfície inferior marrom, mas têm lobos mais estreitos, $0,8-1,5 \mathrm{~mm}$, isídios erumpentes e produz somente ácido protocetrárico na medula (Nash et al. 1995).

Xanthoparmelia subramigera é frequente nos costões rochosos catarinenses e mais rara nos costões paranaenses. Ao contrário das demais espécies do gênero que ocorrem na área de estudo, cresce isolada, formando grandes circunferências, em locais ensolarados e às vezes próxima à vegetação arbustiva.

Espécimes selecionados examinados - BRASIL. Paraná: Guaratuba, Praia de Brejatuba, 02/IX/2011,E. Gumboski \& F. Beilke $2587 b$ (UPCB); Matinhos, Ilha das Tartarugas, 21/III/2008, E. Gumboski \& F. Beilke 1846 (UPCB). Santa Catarina: Governador Celso Ramos, Praia do Sicial, 02/ IV/2011, A. Gerlach 660 (UPCB). Florianópolis, Praia da Joaquina, 18/II/2011, A. Gerlach 645 (UPCB); ibid, Praia do Gravatá, 06/IX/2010, A. Gerlach 405 (UPCB). Bombinhas, Praia da Sepultura, 07/XII/2010, A. Gerlach 530 (UPCB).

\section{Agradecimentos}

Os autores agradecem a curadoria do herbário ICN pelo empréstimo. Aos biólogos Emerson Luiz Gumboski e Flávio Beilke pelo auxilio em coletas. A FATMA (Fundação do Meio Ambiente) pela licença de coleta concedida. A primeira autora agradece a CAPES (Coordenadoria de Aperfeiçoamento do Pessoal do Ensino Superior) pela concessão de bolsa de Mestrado (REUNI).

\section{Referências bibliográficas}

Barbosa, S.B.; Marcelli, M.P. \& Machado, S.R. 2009. Evaluation of different protocols for anatomical studies in Parmeliaceae (lichenized Ascomycota). Micron 40: 218-225.
Benatti, M.N. \& Marcelli, M.P. 2008. Espécies de Parmotrema (Parmeliaceae, Ascomycetes liquenizados) com máculas reticulares do litoral centro-sul do Estado de São Paulo, Brasil. Hoehnea 35: 75-90.

Benatti, M.N. \& Marcelli, M.P. 2009a. Espécies de Parmotrema (Parmeliaceae, Ascomycetes liquenizados) com medula pigmentada do litoral centro-sul do Estado de São Paulo. Hoehnea 36: 597-612.

Benatti, M.N. \& Marcelli, M.P. 2009b. Espécies de Parmotrema (Parmeliaceae, Ascomycota) do litoral centro-sul do Estado de São Paulo, Brasil. I. Grupos químicos girofórico e lecanórico. Acta Botanica Brasilica 23: 1012-1026.

Benatti, M.N.; Marcelli, M.P. \& Elix, J.A. 2008. Three new species of Parmotrema containing salazinic acid from the coast of São Paulo State, southeastern Brazil. Mycotaxon 103: 41-52.

Blanco, O.; Crespo, A.; Divakar, P.K.; Esslinger, T.L.; Hawksworth, D.L. \& Lumbsch, H.T. 2004. Melanelixia and Melanohalea, two new genera segregated from Melanelia (Parmeliaceae) based on molecular and morphological data. Mycological Research 108 (8): 873-884.

Brako, L.; Dibben, M.J. \& Amaral, I. 1985. Preliminary notes on the macrolichens of Serra do Cachimbo, northcentral Brazil. Acta Amazonica, supl., 15: 123- 135.

Brodo, I.M.; Sharnoff, S.D. \& Sharnoff, S. 2001. Lichens of North America. New Haven, Yale University Press.

Carvalho, P.; Figueira, R. \& Jones, M.P. 2008. Os líquenes e fungos liquenícolas (Fungi) dos arquipélagos da Madeira e das Selvagens. Pp. 95-122. In: Borges, P.A.U.; Abreu, C.; Aguiar, A.M.F.; Carvalho, P.; Jardim, R.; Melo, I.; Oliveira, P.; Sergio, C.; Serrano, A.R.M. \& Vieira, P. (Eds.). A list of the terrestrial fungi, flora and fauna of Madeira and Selvagens Archipelagos. Açores, Direcção Regional do Ambiente da Madeira and Universidade dos Açores, Funchal and Angra do Heroísmo.

Crespo, A.; Blanco, O. \& Hawksworth, D.L. 2001. The potencial of mitochondrial DNA for stablishing phylogeny and stabilizing generic concepts in the parmelioid lichens. Taxon 50: 807-819.

Crespo, A.; Ferencova, Z.; Pérez-Ortega, S.; Elix, J.A. \& Divakar, P.K. 2010. Austroparmelina, a new Australasian lineage in parmelioid lichens (Parmeliaceae, Ascomycota). Systematics and Biodiversity 8(2): 209-221.

Crespo, A.; Divakar, P.K. \& Hawksworth, D.L. 2011. Generic concepts in parmelioid lichens, and the phylogenetic value of characters used in their circumscription. The Lichenologist 43(6): 511-535.

Culberson, C.F. \& Ammann, K. 1979. Standard method zur Dünnschichtchomatographie von Flechtensubstanzen. Herzogia 5: 1-24.

Divakar, P.K. \& Upreti, D.K. 2003. Additional notes and new records on the lichen genus Hypotrachyna (Parmeliaceae) from India. Mycotaxon 86: 67-76.

Divakar, P.K.; Lumbsch, H.T.; Ferencova, Z.; Del Prado, R. \& Crespo, A. 2010. Remototrachyna, a newly recognized tropical lineage of lichens in the Hypotrachyna clade (Parmeliaceae, Ascomycota), originated in the Indian subcontinent. American Journal of Botany 97(4): 579-590.

Eliasaro, S. 2006. Checklist of lichens and lichenicolous fungi of Paraná (Brazil). Versão 1 Setembro de 2006. http://www.checklists.de.

Eliasaro, S.; Adler, M. \& Elix, J. 1998. The species of Hypotrachyna (Parmeliaceae, Lichenized Ascomycotina) from the Segundo Planalto in the state of Paraná, Brazil. Mycotaxon 69: 255-270.

Eliasaro, S. \& Adler, M.T. 2002. Flavoparmelia and Xanthoparmelia (Parmeliaceae, lichenized Ascomycotina) of the segundo planalto of Paraná (Brazil). Mitteilungen aus dem Institut für Allgemeine Botanik Hamburg 30-32: 25-34.

Eliasaro, S.; Veiga, P.W.; Donha, C. G. \& Nogueira, L. 2009. Inventário de macroliquens epífitos sobre árvores utilizadas em arborização urbana em Curitiba, Paraná, Brasil: subsídio para biomonitoramento urbano. Biotemas 22: 1-8.

Elix, J.A. 1993. Progress in the generic delimitation of Parmelia sensu lato lichens (Ascomycotina: Parmeliaceae) and a synoptic key to the Parmeliaceae. The Bryologist 96(3): 359-383.

Elix, J.A. 1994a. Canoparmelia. In: Flora of Australia, Lichens. Introduction Lecanorales 2. 55: 21-31. Canberra, Australian Biological Resources Study.

Elix, J.A. 1994b. Hypotrachyna. Flora of Australia 55: 49-59. 
Elix, J.A. \& Ernst-Russell, K.D. 1993. A catalogue of standardized thin layer chromatographic data and biosynthetic relationships for lichen substances. 2nd ed. Camberra, Australian National University Canberra.

Elix, J.A. \& Nash III, T.H. 1997. A Monograph of the Lichen Genus Pseudoparmelia (Ascomycotina, Parmeliaceae). The Bryologist 100(4): 482-498.

Fleig, M. 1995. Lichens from "Casa de Pedra" and surroundings, Bagé, Rio Grande do Sul, Brazil. P. 415-426. In: Daniels, F.J.A.; Schulz, M. \& Peine, J. (Eds.). Flechten Follman. Contributions to Lichenology in honour of Gerhard Follman. Colonia, The Geobotanical and Phytotaxonomical study group, Botanical Institute, Germany, University of Cologne.

Fleig, M. 1999. New species in the lichen genus Parmotrema (Parmeliaceae Ascomycotina) from southern Brazil. Mycotaxon 71: 199-206.

Fleig, M. \& Riquelme, I. 1991. Liquens de Piraputanga, Mato Grosso do Sul, Brasil. Acta Botanica Brasilica 5: 3-12.

Giordani, P.; Nicora, P.; Rellini, I.; Brunialti, G. \& Elix, J.A. 2002. The lichen genus Xanthoparmelia (Ascomycotina, Parmeliaceae) in Italy. The Lichenologist 34: 189-198.

Gumboski, E.L. 2011. Cladonia (Cladoniaceae, Ascomycota liquenizados) em ambientes de restingas e costões rochosos no Paraná e Santa Catarina. Dissertação de Mestrado em Botânica. Universidade Federal do Paraná, Curitiba.

Gumboski, E.L. \& Eliasaro, S. 2011. Cladonia litoralis (Cladoniaceae), a new species from southern Brazil. The Bryologist 114 (4): 665-667.

Hale, M.E. 1964. The Parmelia conspersa group in North America and Europe. The Bryologist 67: 462-473.

Hale, M.E. 1965. A Monograph of the Parmelia subgenus Amphigymnia. Contributions from the United States National Herbarium 36(5): 193-358.

Hale, M.E. 1971. Morden-Smithsonian Expedition to Dominica: The Lichens (Parmeliaceae). Smithsonian Contributions to Botany 4: 1-25.

Hale, M.E. 1974. Notes on species of Parmotrema (Lichenes: Parmeliaceae) containing yellow pigments. Mycotaxon 1: 105-116.

Hale, M.E. 1975. A Revision of the Lichen Genus Hypotrachyna (Parmeliaceae) in Tropical America. Smithsonian Contributions to Botany 25: $1-73$.

Hale, M.E. 1976. A Monograph of the Lichen Genus Pseudoparmelia Lynge (Parmeliaceae). Smithsonian Contributions to Botany 31: 1-62.

Hale, M.E. 1977. New species in the lichen genus Parmotrema Mass. Mycotaxon 5(2): 432-448.

Hale, M.E. 1989. New species in the lichens genus Xanthoparmelia (Ascomycotina: Parmeliaceae). Mycotaxon 34(2): 541-564.

Hale, M.E. 1990. A Synopsis of the Lichen Genus Xanthoparmelia (Vainio) Hale (Ascomycotina, Parmeliaceae). Smithsonian Contributions to Botany 74: 1-250.

Kirk, P.M.; Cannon, P.F.; Minter, D.W. \& Stalpers, J.A. 2008. Ainsworth \& Bisby's Dictyonary of Fungi. 10th ed. CABI International. Egham.

Krog, H. \& Swinscow, T.D.V. 1981. Parmelia subgenus Amphigymnia (lichens) in East Africa. Bulletin of British Museum of Natural History (Bot.) 9(3): 143-231.

Kurokawa, S. 1974. Four new species of Parmelia from Brazil. Bulletin of the National Science Museum 17: 297-301.

Kurokawa, S. 1989. Studies on Japanese species of Xanthoparmelia (Parmeliaceae) (2). The Journal of Japanese Botany 64(10): 289-298.

López-Figueiras, M. 1986. Censo de macrolíquenes de los Estados Falcón, Lara, Mérida, Táchira y Trujillo. Venezuela, Mérida, Talleres Gráficos Universitarios.

Lynge, B. 1914. Die Flechten der ersten Regnellschen Expedition. Die Gattungen Pseudoparmelia gen. nov. und Parmelia Ach. Arkiv för Botanik 13(13): 1-172.

Marcelli, M.P. 1991. Aspects of the foliose lichen flora of the southerncentral coast of São Paulo State, Brazil. Pp. 151-170. In: Galloway, D.J. (Ed.). Tropical lichens: Their systematics, conservation, and ecology. Systematics Association Special Volume 43. Oxford, Clarendon Press.

Marcelli, M.P. 1998. History and current knowledge of Brazilian Lichenology. Pp. 25-45. In: Marcelli M.P.E. \& Seaward, M.R.D. (Eds.). Lichenology in Latin América: history, current knowledge and applications. São Paulo, CETESB.
Marcelli, M.P.; Jungbluth, P.; Benatti, M.N.; Spielmann, A.A.; Canêz, L.S.; Cunha, I.P.R. \& Martins, M.F.N. 2007. Some new species and combinations of Brazilian lichenized fungi. Bibliotheca lichenologica 96: 209-227.

Marcelli, M.P. \& Benatti, M.N. 2008. Espécies de Parmotrema (Parmeliaceae, Ascomycetes liquenizados) com rizinas dimórficas do litoral centro-sul do Estado de São Paulo. Hoehnea 35(2): 171-183.

Marcelli, M.P.; Benatti, M.N. \& Elix, J.A. 2008. New species of Parmotrema containing protocetraric or stictic acids from the coast of São Paulo State, southeastern Brazil. Mycotaxon 105: 235-248.

Marcelli, M.P. \& Benatti, M.N. 2010a. Espécies de Parmotrema (Parmeliaceae, Ascomycetes liquenizados) com ácidos graxos ou atranorina medulares do litoral centro-sul do Estado de São Paulo. Hoehnea 37: 117-129.

Marcelli, M.P. \& Benatti, M.N. 2010b. Espécies de Parmotrema (Parmeliaceae, Ascomycota) do litoral centro-sul do Estado de São Paulo II. Grupos químicos norestíctico e salazínico. Acta Botanica Brasilica 24: 153-168.

Ministério do Meio Ambiente (MMA). 2010. Gerência de Biodiversidade Aquática e Recursos Pesqueiros. Panorama da conservação dos ecossistemas costeiros e marinhos no Brasil. Brasília, MMA/ SBF/GBA.

Nash III, T.H. \& Elix, J.A. 1987. New species and new reports in the Parmeliaceae (Lichenized Ascomycotina) from South Africa and Australia. Mycotaxon 29: 467-476.

Nash III, T.H;, Gries, C. \& Elix J.A. 1995. A revision of the lichen genus Xanthoparmelia in South America. Bibliotheca Lichenologica 56: 1-158.

Nash III, T.H. \& Elix, J.A. 2002a. Canoparmelia. Pp. 122-125. In: Nash III, T.H.; Ryan, B.D.; Gries, C.\& Bungartz, F. (Eds.). Lichen Flora of the greater Sonoran Desert Region. Volume 1. Arizona, USA, Arizona State University, Tempe.

Nash III, T.H. \& Elix, J.A. 2002b. Parmotrema. Pp. 318-329.In: Nash III, T.H.; Ryan, B.D.; Gries, C.\& Bungartz, F. (Eds.). Lichen Flora of the greater Sonoran Desert Region. Volume 1. Arizona, USA, Arizona State University, Tempe.

Osorio, H.S. 1972. Contribution to the lichen flora of Uruguai VII. A preliminary catalogue. Comunicaciones Botánicas del Museo de Historia Natural de Montevideo 4(56): 1-46.

Osorio, H.S. 1977. Contribution to the lichen flora of Brazil II. Lichens from Guarapuava, Paraná State. Dusenia 10: 101-102.

Osorio, H.S. 1982. Contribution to the lichen flora of Argentina XIV. Lichens from entre Rios Province. Comunicationes Botanicas del Museo de Historia Natural de Montevideo 64(4): 1-8.

Osorio, H.S. 1997. Contribution to the lichen flora of Brazil. XXXIV. Lichens from Laguna, Santa Catarina State. Comunicaciones Botánicas del Museo deHistoria Natural de Montevideo 108(6): 1-4.

Osorio, H.S.; Aguiar, L.W. \& Homrich, M.H. 1981. Contribution to the Lichen Flora of Brazil VI. New or additional records from Rio Grande do Sul State. The Bryologist 84(1): 79-81.

Osorio, H.S. \& Fleig, M. 1984a. Contribution to the lichen flora of Brazil. XIII. Maritime lichens from Torres, Rio Grande do Sul State. International Journal of Mycology and Lichenology 1(3): 273-279.

Osorio, H.S. \& Fleig, M. 1984b. Contribution to the lichen flora of Brazil. XV. Lichens from Torre Sul and Itapeva, Torres, Rio Grande do Sul State. Comunicaciones Botánicas del Museo de Historia Natural de Montevideo 4(67): 1-7.

Osorio, H.S. \& Fleig, M. 1990. Contribution to the lichen flora of Brazil. XVII. Additions and corrections to the Rio Grande do Sul lichen flora. Comunicaciones Botánicas del Museo de Historia Natural de Montevideo 5(96): 1-6.

Sipman, H. \& Aubel, R.J.M.T. Van. 1992. New Parmeliaceae (Lichenes) from the Guianas and surroundings. Mycotaxon 44(1): 1-12.

Sipman, H.J.M.; Elix, J.A. \& Nash III, T.H. 2009. Hypotrachyna (Parmeliaceae, Lichenized Fungi). Flora Neotropica Monograph 104: 1-173.

Spielmann, A.A. \& Marcelli, M.P. 2008. Parmeliaceae (Ascomycota liquenizados) nos barrancos e peraus da encosta da Serra Geral, Vale do Rio Pardo, Rio Grande do Sul, Brasil. II. Gêneros Canoparmelia, Hypotrachyna, Myelochroa, Parmelinopsis e Relicina. Iheringia, Série Botânica, 63(2): 193-212. 
Spielmann, A.A. \& Marcelli, M.P. 2009. Parmotrema s.l. (Parmeliaceae, lichenized Ascomycota) from Serra Geral slopes in central Rio Grande do Sul State, Brazil. Hoehnea 36(4): 551-595.

Swinscow T.D.V. \& Krog, H. 1988. Macrolichens of East Africa. London, British Museum of Natural History.

Taylor, C.J. 1967. The lichens of Ohio. Part I. Foliose lichens. The Ohio Biological Survey. Columbia, The Ohio State University Press.
Taylor, C.J. 1968. The lichens of Ohio. Part II. Fruticose and lichens. The Ohio Biological Survey. Columbia, The Ohio State University Press.

Wang, X.Y.; Koh, Y.J. \& Hur, J-S. 2008. Taxonomic study on the lichen genus Xanthoparmelia (Ascomycotina, Parmeliaceae) in Korea. Mycobiology 36(4): 203-210.

Winnem, B. 1975. Parmelia subgenus Amphigymnia in Ethiopia. Norwegian Journal of Botany 22: 139-166. 